\title{
ESTUDO DE CASO: ANÁLISE DE PATOLOGIAS ESTRUTURAIS EM UMA RESIDÊNCIA UNIFAMILIAR CAUSADAS POR RECALQUE ${ }^{1}$
}

\author{
KARLAN GALENO RODRIGUES DE CARVALHO (UNI FSA) ${ }^{2}$ \\ ELISVALDO PEREIRA DA SILVA (UNI FSA) ${ }^{3}$ \\ FRANCISCO HENRIQUE CARVALHO OLIVEIRA (UNI FSA) ${ }^{4}$ \\ JADAÍAS SOUSA DUAILIBE FILHO (UNI FSA) ${ }^{5}$ \\ WELLYTON SOARES LIMA (UNI FSA) ${ }^{6}$ \\ MARIA GABRIELLE FERNANDES SILVA MENDES (UNI FSA) ${ }^{7}$ \\ DIEGO SILVA FERREIRA (UNI FSA) ${ }^{8}$
}

\section{RESUMO}

Nas edificações, as manifestações patológicas podem ser apresentadas de diversas formas e causadas por inúmeros motivos, dentre os quais, está o fenômeno do recalque. Há uma grande dificuldade na análise desse problema, não somente pelo fato da infraestrutura da edificação está soterrada, mas também, em alguns casos, há uma indeterminação das camadas constituintes do solo, o que torna importante o estudo de sondagem no local da fundação, quando possível, de forma a obter todas as informações necessárias para a identificação do problema. O objetivo deste trabalho é servir como parâmetro de estudo através da identificação, possível prevenção e solução das manifestações patológicas encontradas em uma residência unifamiliar, feito pela identificação visual e informações da construção. A residência encontra-se localizada na rua: Alcides Freitas, $\mathrm{N}^{\circ}$ 475, bairro: Matinha em Teresina-PI, onde foram realizadas as medições e classificações de fissuras, trincas e rachaduras. Concluiu-se que o imóvel apresentou diversos recalques ocasionado as diversas manifestações patológicas encontradas, devido ao despejo de pó de serragem no terreno, antes da construção da edificação.

Palavras-Chave: Fundação. Fissuras. Manifestações patológicas.

\footnotetext{
${ }^{1}$ Trabalho apresentado no Congresso Brasileiro Ciência Sociedade (CBCS 2019), promovido pelo Centro Universitário Santo Agostinho, de 03 a 05 de outubro de 2019, em Teresina-PI.

${ }^{2}$ Graduando em Engenharia Civil, Centro Universitário Santo Agostinho, karlangaleno10@gmail.com

${ }^{3}$ Graduando em Engenharia Civil, Centro Universitário Santo Agostinho, mirandasp10@gmail.com

${ }^{4}$ Graduando em Engenharia Civil, Centro Universitário Santo Agostinho, henrire007@gmail.com

${ }^{5}$ Graduando em Engenharia Civil, Centro Universitário Santo Agostinho, jadaiasduailibe55@gmail.com

${ }^{6}$ Graduando em Engenharia Civil, Centro Universitário Santo Agostinho,wellytonsoareslima@gmail.com

${ }^{7}$ Graduando em Engenharia Civil, Centro Universitário Santo Agostinho, gabrielle_fernandes@outlook.com

${ }^{8}$ Mestre em Engenharia de materiais, Instituto Federal do Piauí, diegof.engenheiro@gmaid
} 
ANAIS CBCS 2019 | 3 a 5 de outubro de 2019 | Centro Universitário Santo Agostinho - Teresina - PI

\section{INTRODUÇÃO}

Segundo Moreira e Ripper (1998), designam-se por Patologia das Estruturas esse novo campo da Engenharia das Construções que se ocupa do estudo das origens, formas de manifestações, consequências e mecanismos de ocorrências das falhas e dos sistemas de degradação das estruturas. Esse estudo é de extrema importância para determinar em quanto tempo deve-se fazer a manutenção, prolongando assim o tempo útil da construção.

Não é de hoje que os problemas patológicos acontecem nas estruturas. Desde o início das construções inúmeras deteriorações contribuíram para a evolução das técnicas construtivas que conhecemos hoje (BRUST, 2015). Segundo Thomaz (2002), foi necessário que surgissem fissuras decorrentes das movimentações térmicas para descobrir que os muros como estruturas únicas costumavam trincar a cada 4 ou 5 metros e prever juntas de dilatação nesses pontos.

As manifestações mais comuns são trincas, fissuras, rachaduras no concreto e infiltrações, fungos, descolamentos, entre outros, em outras partes das edificações (LOTTERMANN, 2013).

Klein et al. (1999) apresenta um levantamento sobre as causas dos danos nas construções, no qual destaca que $47 \%$ dos problemas são de trincas e fissuras pela movimentação estrutural e $26 \%$ são por recalque de fundações.

Segundo Do Carmo:

O conhecimento da causa que gerou o problema é importante para que se possa prescrever a terapêutica adequada para o problema em questão, uma vez que se tratarmos os sintomas sem eliminar a causa, o problema tende a se manifestar novamente (DO CARMO, 2003, p. 11).

Em painéis de alvenaria as fissuras podem se apresentar nas direções horizontal, vertical, diagonal, ou uma combinação destas. Quando verticais ou diagonais, elas podem ser retas, atravessando unidades e juntas, ou podem ter aspecto escalonado, passando apenas pelas juntas. A forma da fissura é influenciada por vários fatores, incluindo a rigidez relativa das juntas com relação às unidades, a presença de aberturas ou outros pontos de fragilidade, as restrições da parede e a causa da fissura. 


\section{CONQEESSOC CIENCIASSOCIEDADE \\ Inovação, Diversidadie e Sustentahilitilatie}

ANAIS CBCS 2019 | 3 a 5 de outubro de 2019 | Centro Universitário Santo Agostinho - Teresina - P

\section{METODOLOGIA}

O método utilizado para a elaboração deste trabalho envolveu pesquisa bibliográfica e estudo de caso. Inicialmente realizou-se uma visita à residência onde encontramos as patologias, cenário do estudo de caso. Nessa visita, avaliou-se o local através da inspeção visual tanto na área interna quanto externa, com registro fotográfico detalhado das anomalias e do local.

Os materiais utilizados na obtenção dos dados foram:

- Fissurômetro;

- Lupa;

- Paquímetro;

Figura 1. Fissurômetro de PVC transparente.

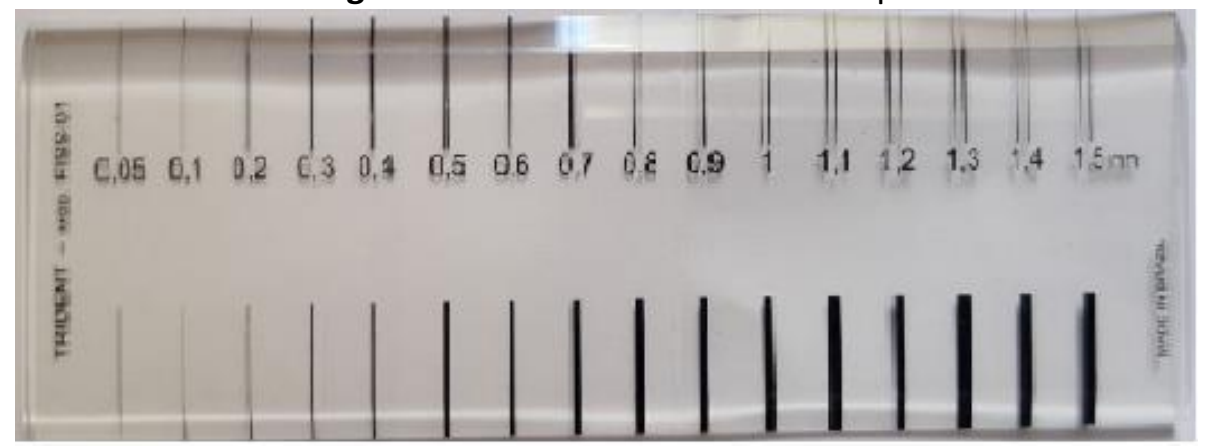

Fonte: Próprio autor, 2019.

Figura 2. Lupa iluminada.

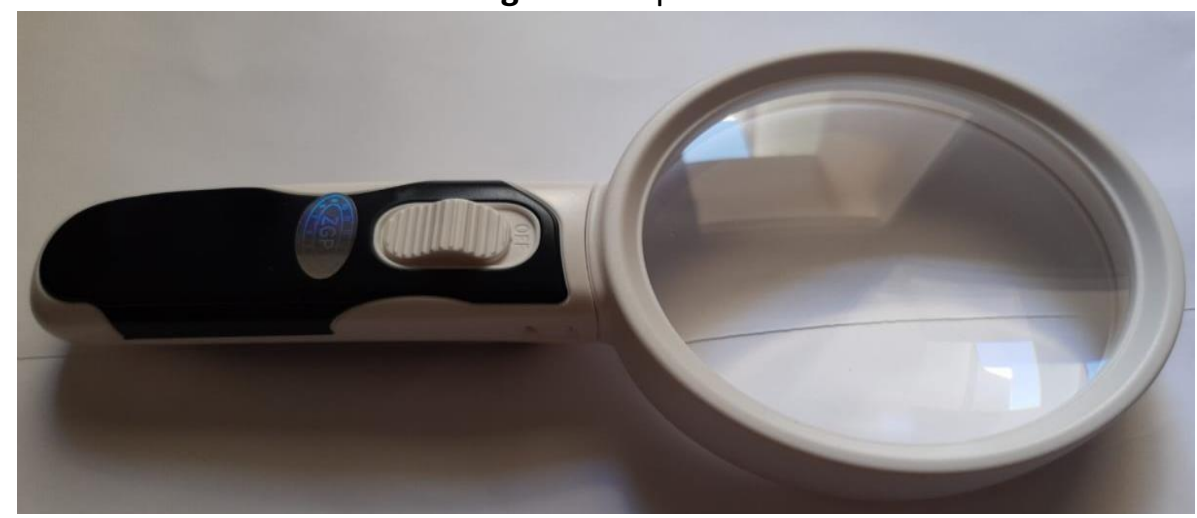

Fonte: Próprio autor, 2019. 


\section{CONGQEESSOCIENCIASSOCIEDADE \\ Inovação, Diversidadie e Sustentahilitilatie}

ANAIS CBCS 2019 | 3 a 5 de outubro de 2019 | Centro Universitário Santo Agostinho - Teresina - PI

Figura 3. Paquímetro digital.

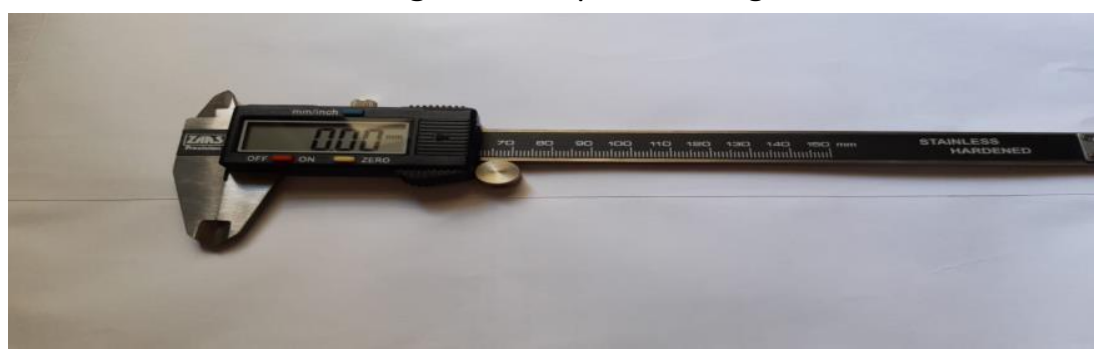

Fonte: Próprio autor, 2019.

A figura 4 mostra as anomalias de acordo com as aberturas em milímetros, que foi utilizada para classificação.

Figura 4. Tabela de classificação das anomalias.

\begin{tabular}{|c|c|}
\hline ANOMALIAS & ABERTURAS (mm) \\
\hline Fissura & até $0, \mathbf{5}$ \\
\hline Trinca & de 0,5 a $\mathbf{1 , 5}$ \\
\hline Rachadura & de 1,5 a 5,0 \\
\hline Fenda & de 5,0 a 10,0 \\
\hline Brecha & Acima de 10,0 \\
\hline
\end{tabular}

Fonte: SILVA, 2019.

\section{RESULTADOS E DISCUSSÃO}

Figura 5. Tabela de classificação das anomalias encontradas na residência.

\begin{tabular}{|l|l|l|}
\hline ANOMALIAS & ABERTURAS $(\mathrm{mm})$ & CLASSIFICAÇÃO \\
\hline 1 & 60,0 & BRECHA \\
\hline 2 & 30,0 & BRECHA \\
\hline 3 & 20,0 & BRECHA \\
\hline 4 & 2,0 & RACHADURA \\
\hline 5 & 3,0 & RACHADURA \\
\hline
\end{tabular}

Fonte: Próprio autor, 2019.

A edificação apresentou manifestações patológicas de diversos tamanhos, espessuras e inclinações, ocasionados por diferentes níveis de recalque da estrutura de fundação. 


\section{cONGQESSO CIENCIASSOCIEDADE > Inovação, Diversidaalle e Sustentahililitaile}

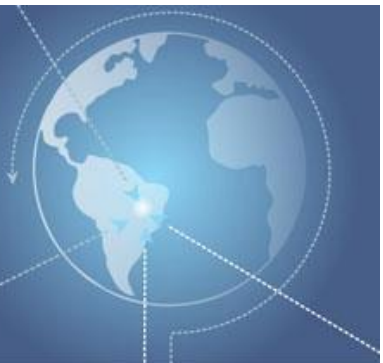

ANAIS CBCS 2019 | 3 a 5 de outubro de 2019 | Centro Universitário Santo Agostinho - Teresina - PI

Figura 6. Anomalia 1 na parede do quarto.

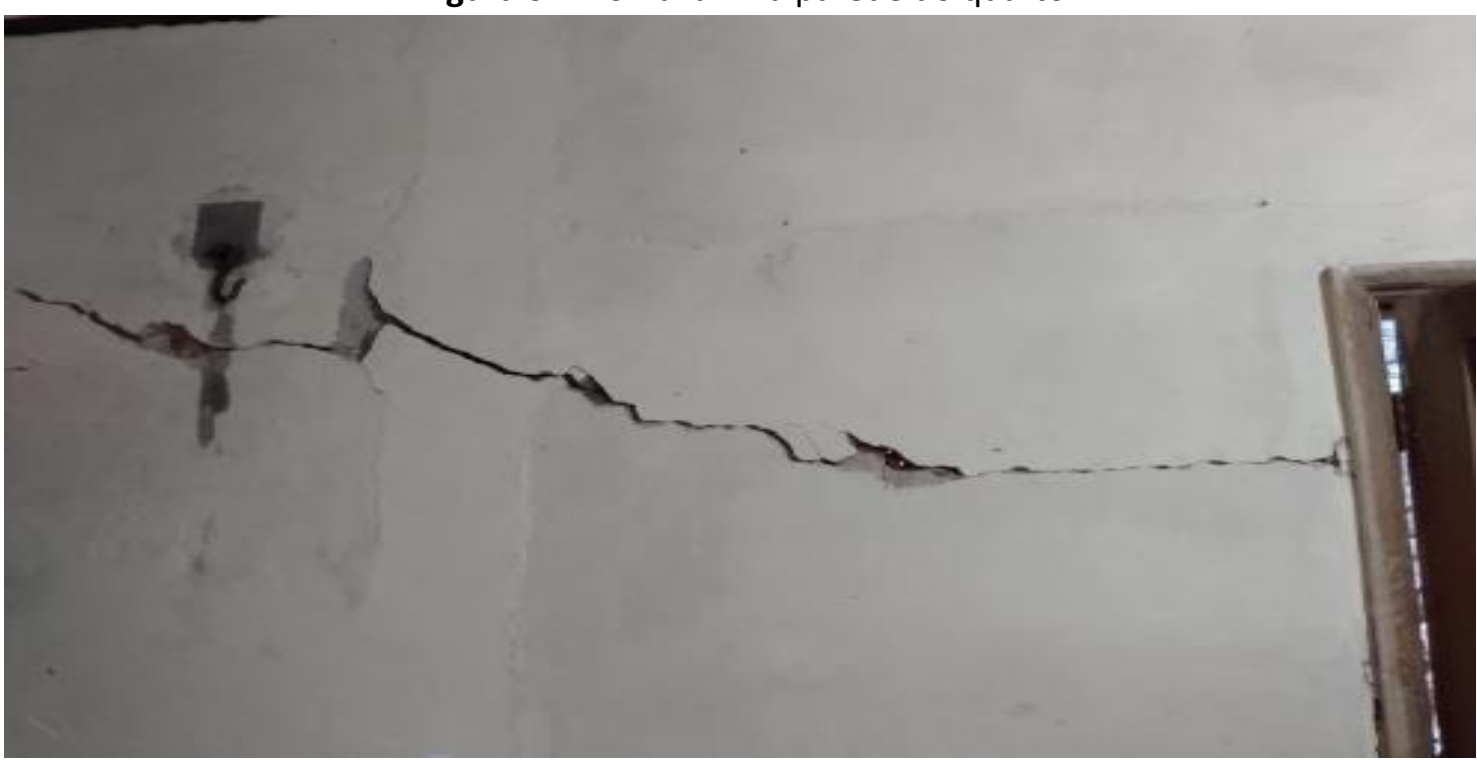

Fonte: Próprio autor, 2019.

Figura 7. Vista externa da figura 6.

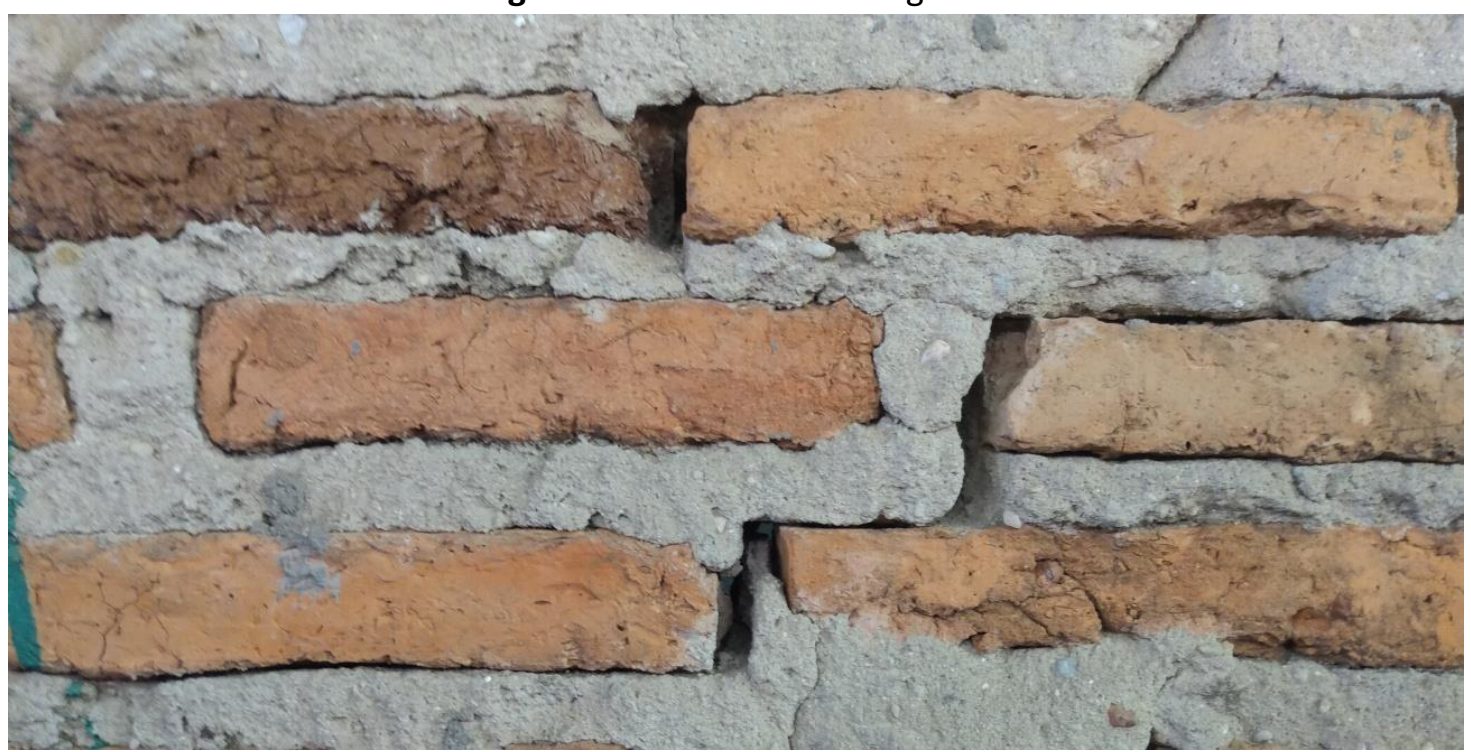

Fonte: Próprio autor, 2019.

Com base nas figuras 6 e 7, vista interna e externa da brecha horizontal, situada na parede do quarto no canto superior da abertura, com espessura de $60 \mathrm{~mm}$, observou-se a indicação por rompimento devido à tração com direção ao ponto de maior recalque. 


\section{cONGQESSOC CIENCIASSOCIEDADE \\ , Inovação, Diversidiatle e Sustentahililitatie}

ANAIS CBCS 2019 | 3 a 5 de outubro de 2019 | Centro Universitário Santo Agostinho - Teresina - PI

Figura 8. Anomalia 2.

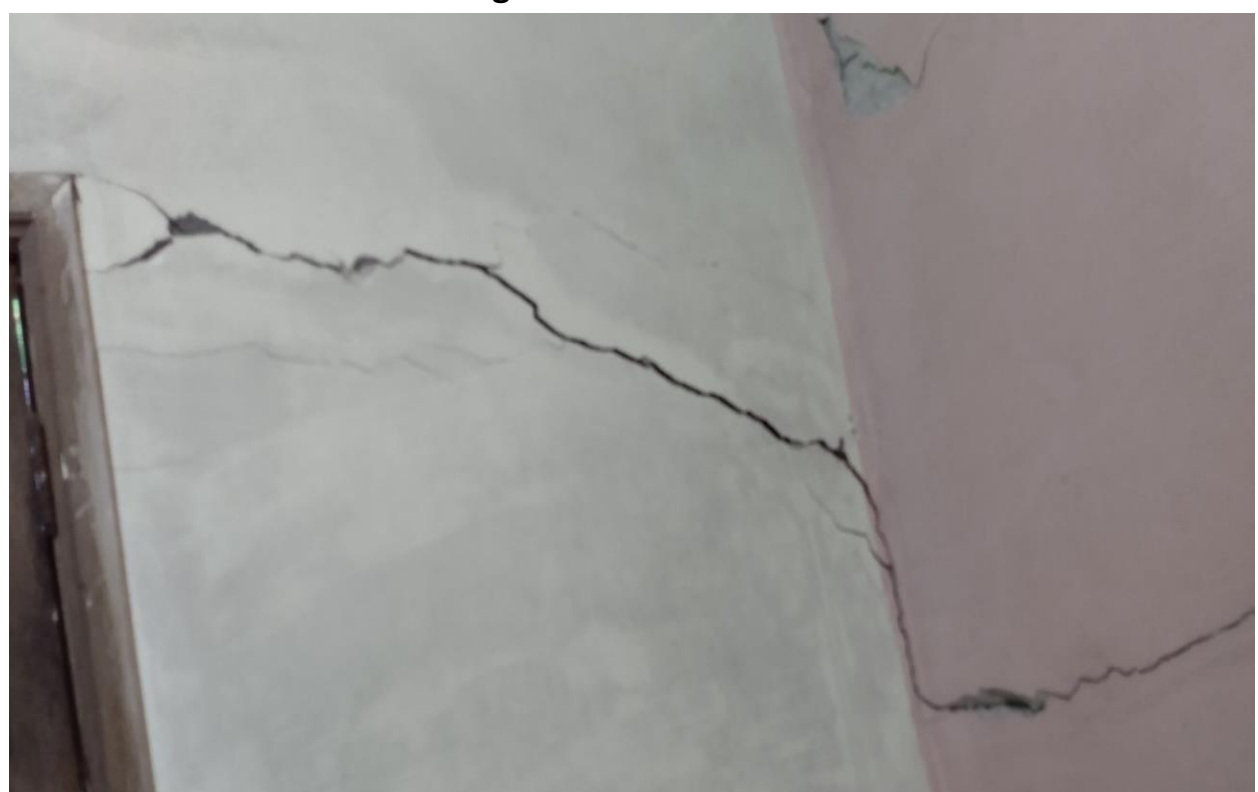

Fonte: Próprio autor, 2019.

Figura 9. Anomalia 3.

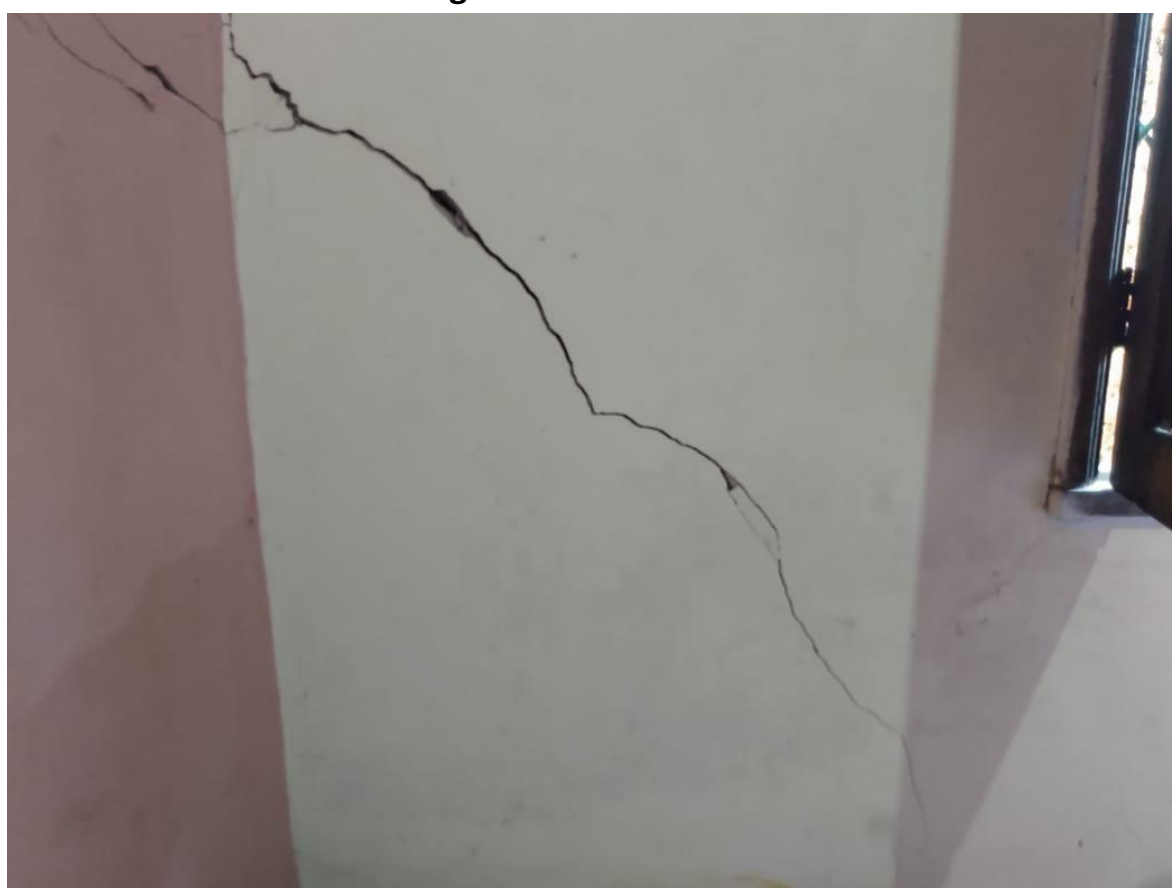

Fonte: Próprio autor, 2019. 


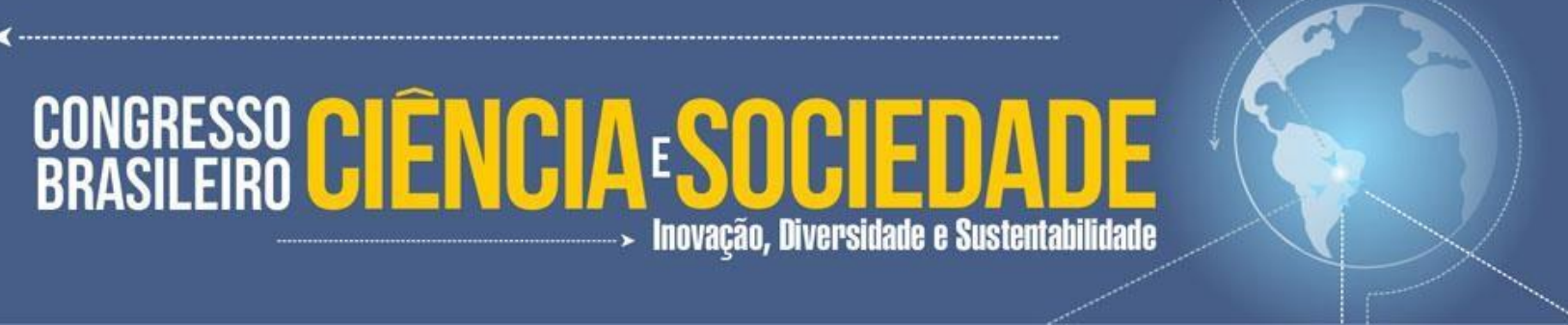

ANAIS CBCS 2019 | 3 a 5 de outubro de 2019 | Centro Universitário Santo Agostinho - Teresina - PI

Figura 10. Anomalia 4.

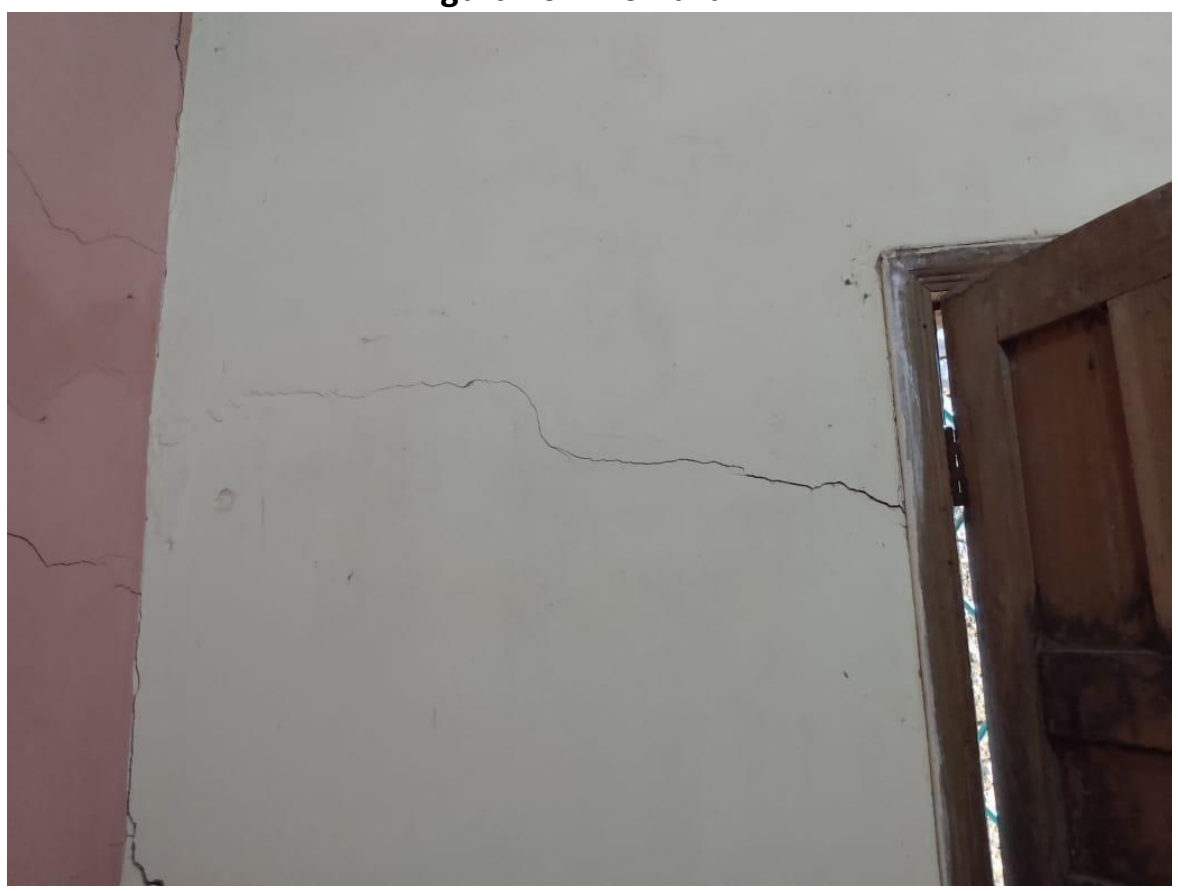

Fonte: Próprio autor, 2019.

Figura 11. Anomalia 5.

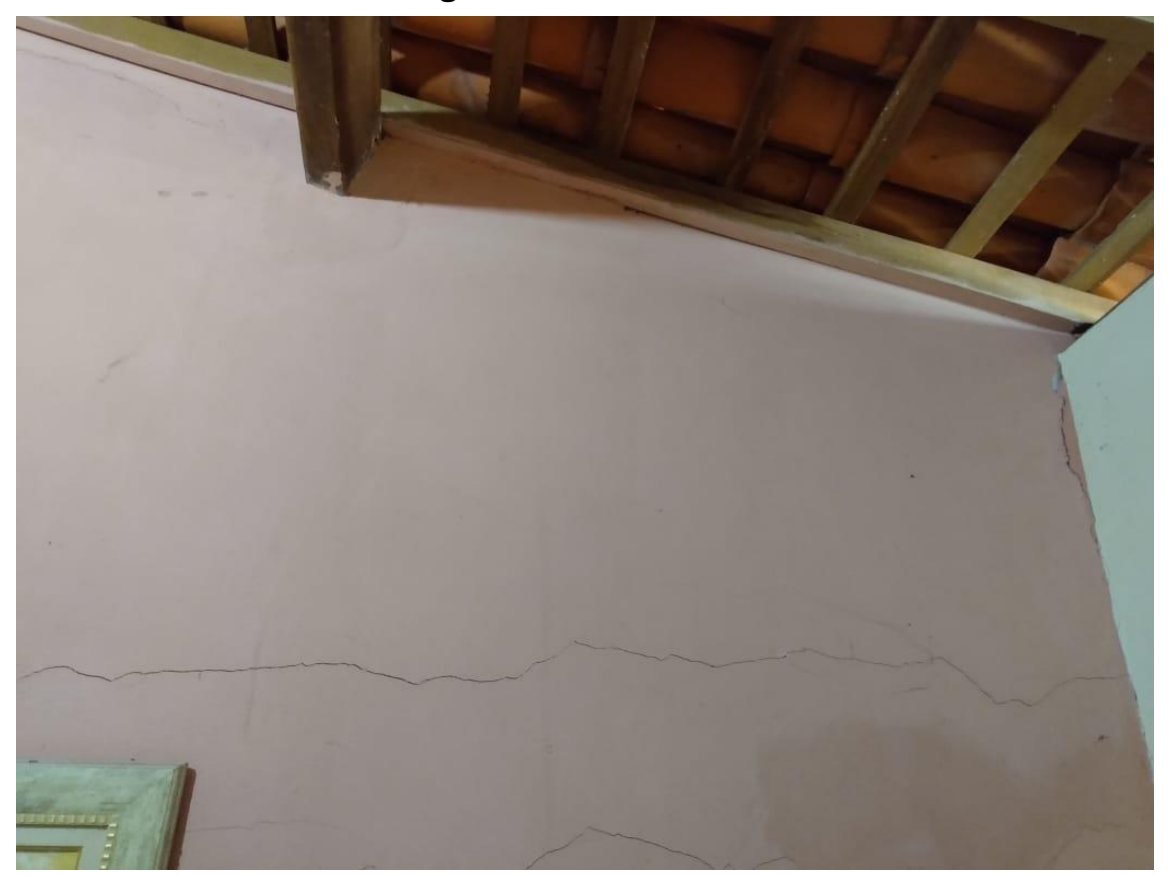

Fonte: Próprio autor, 2019. 


\section{conweESSOOCIENCIA:SOCIEDADE Inovação, Diversidadie e Sustentahilitiladie}

ANAIS CBCS 2019 | 3 a 5 de outubro de 2019 | Centro Universitário Santo Agostinho - Teresina - PI

Figura 12. Configurações das fissuras em algumas situações de recalques.

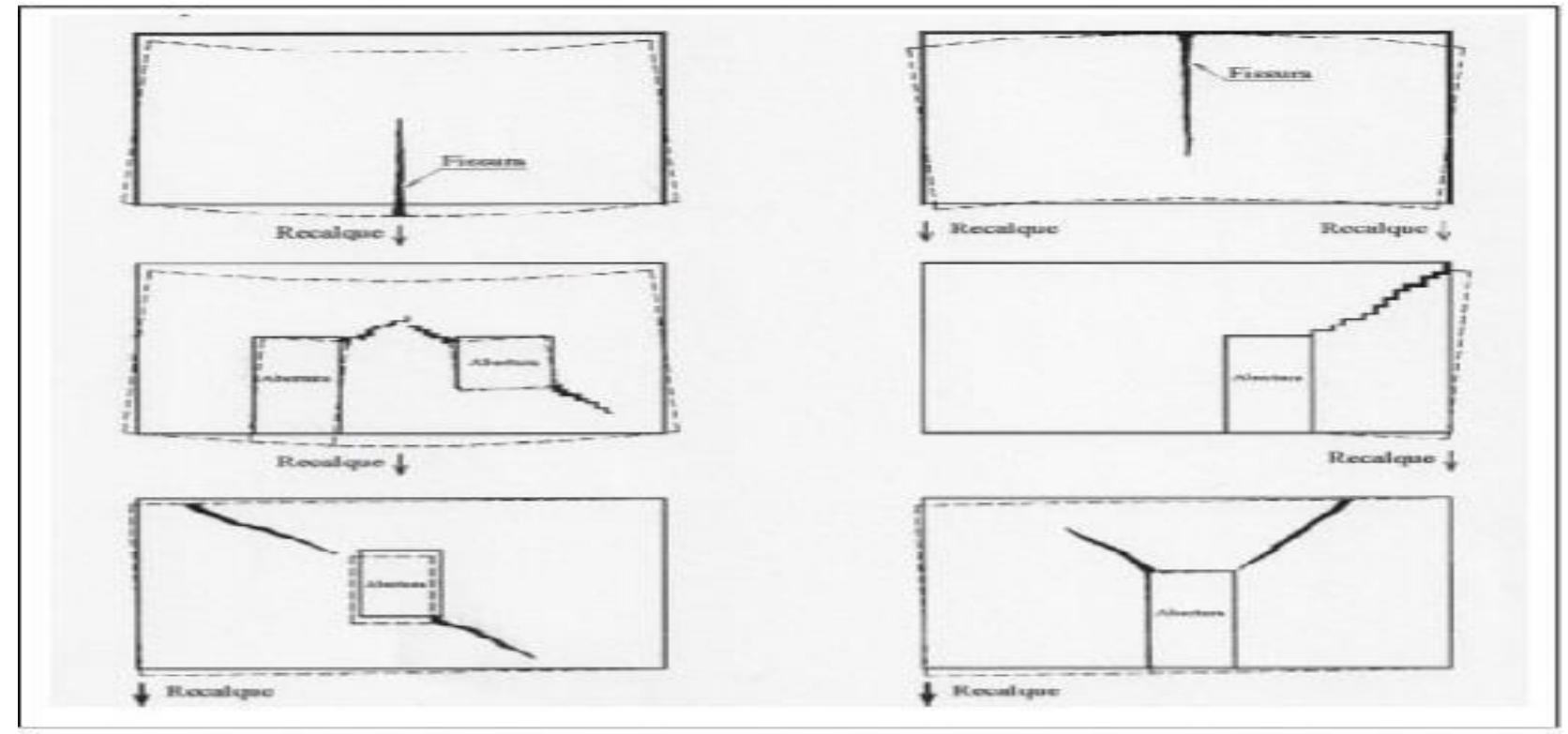

Fonte: VALLE, 2019.

As anomalias mostradas nas figuras 6 a 11, apresentam padrões típicos de recalques da fundação em solo criado ou aterro. No caso estudado a edificação foi construída em aterro criado com presença considerável de pó de serragem, tendo como origem a ausência, insuficiência ou ineficiência das investigações geotécnicas.

É importante mencionar que detalhes construtivos específicos de vinculação dos diferentes elementos que normalmente compõem uma edificação, além de efeitos combinados de movimentos causados por outra origem que não deslocamentos, tornam, nos casos reais, bastante complexas a definição e identificação dos movimentos a partir da fissuração apresentada, sendo necessária a realização de acompanhamento ou controle de recalques para identificação precisa das causas originais dos problemas patológicos.

Os danos causados pelos recalques expostos são divididos em três grupos: visuais e estéticos, danos comprometendo o uso e funcionalidade da edificação e danos estruturais pondo em risco a segurança dos usuários, devendo ser motivo de intervenção imediata para solução das causas originais. 


\section{conghESSO CIENCIAESOCIEDADE Inovação, Diversidadie e Sustentahililitadie}

ANAIS CBCS 2019 | 3 a 5 de outubro de 2019 | Centro Universitário Santo Agostinho - Teresina - PI

Nesta obra a solução pode ser o reforço das fundações existentes, com aterro adequado para evitar os recalques, ou também a execução de novas fundações (reconstrução) desprezando as existentes como elemento resistente. Elaborar uma solução para o problema requer um trabalho de especialistas, aliando técnicas de engenharia de estruturas e solo.

\section{CONSIDERAÇÕES FINAIS/CONCLUSÕES}

As informações colhidas mostram que as manifestações patológicas que surgiram nas paredes, do caso estudando, poderiam ter sido evitadas com a realização da investigação de subsolo adequada. O estudo preliminar para a elaboração do projeto não foi eficiente, pois não houve a consideração das características do terreno.

Este trabalho descreveu as causas de recalques de fundações e a identificação e mensuração das manifestações patológicas decorrentes desses movimentos. O objetivo foi auxiliar na identificação da existência de movimentos de fundações através das patologias apresentadas, enfatizando a importância das investigações geotécnicas.

\section{REFERÊNCIAS}

ALMEIDA, V. Trabalho de Tecnologia das Construções. Recuperação de fundações, janeiro 2009. BRUST, D. MANIFESTAÇÕES PATOLÓGICAS CAUSADAS POR RECALQUE DE FUNDAÇÃO: DIAGNÓSTICO DO SURGIMENTO DE FISSURAS NA ALVENARIA DE UMA CASA POPULAR EM PANAMBI/RS, 2015.

DO CARMO, P. O. Patologia das construções. Santa Maria, Programa de atualização profissional CREA - RS, 2003.

FALEIROS, L, et al. Reforço de Fundações; 2013.

IOSHIMOTO, E. Incidência de Manifestações Patológicas em Edificações Habitacionais. São Paulo: IPT, 1994. 


\section{cONQPESSOC CIENCIA:SOCIEDADE

ANAIS CBCS 2019 | 3 a 5 de outubro de 2019 | Centro Universitário Santo Agostinho - Teresina - PI

KLEIN, D. L.; CAMPAGNOLO, J. L.; FUKGI, L. C. P. S. Curso de patologia das construções. Porto Alegre: IBAPE, 1999.

LOTTERMANN, F. N. Patologias em estruturas de concreto: Estudo de Caso. 2013. 66 f. Trabalho de Conclusão do Curso de Graduação em Engenharia Civil apresentado como requisito parcial para obtenção do título de Engenheiro Civil da Universidade Regional do Noroeste do Estado do Rio Grande do Sul, ljuí, 2013.

SOUZA, V. C. M; RIPPER, T. Patologia, recuperação e reforço de estruturas de concreto. São Paulo: Pini, 1998.

THOMAZ, E. Trincas em edifícios: causas, prevenção e recuperação. São Paulo: Editora PINI, 2002. 